\title{
Activity profile of top-class association football referees in relation to fitness-test performance and match standard
}

\author{
JAVIER MALLO , ENRIOUE NAVARRO , JOSE MARÍA GARCIA ARANDA , \& \\ WERNER F. HELSEN
}

Faculty of Physical Activity and Sport Science, Politechnical University of Madrid, Madrid, Spain, FIFA, Zurich, Switzerland, and Department of Biomedical Kinesiology, Katholieke Universiteit Leuven, Heverlee (Leuven), Belgium

\begin{abstract}
The aim of this study was to examine the kinematic activity profiles, cardiovascular responses and physical fitness of topclass football referees $(n=11)$ during the FIFA Confederations Cup 2005. Computerised match-analyses ( $n=9)$ were performed with a two-dimensional photogrammetric video system, and the cardiovascular demand imposed on the referees $(n=12)$ was measured using heart rate recordings. Total distance covered was $10,218, \mathrm{~s}=643 \mathrm{~m}$ of which 3531 , $s=510 \mathrm{~m}$ was covered at high intensities $\left(>3.6 \mathrm{~m} \cdot \mathrm{s}^{-1}\right)$. Both total distance covered $\left(r^{2}=0.59 ; P=0.02\right)$ and highintensity activities $\left(r^{2}=0.44 ; P=0.05\right)$ were related to the distance covered by the ball in the same match. The referees ran at high speed $37 \%$ further $(P=0.01)$ in the actual tournament than during under-17 top-level officiating. After the 5min interval during which high-speed running peaked, in the following $5 \mathrm{~min}$ the performance was reduced by $19 \%$ $(P=0.01)$ in relation to the mean of the game. Mean heart rate was $161, s=9 \mathrm{~b} \cdot \min ^{-1}(86, s=3 \%$ of maximal heart rate $\left(\mathrm{HR}_{\max }\right)$ ). Mean heart rate (expressed as percentage of $\left.\mathrm{HR}_{\max }\right)$ was related in part $\left(r^{2}=0.36 ; P<0.01\right)$ to the number of high-intensity activities performed in the same 5-min interval. The results of this study show that: (1) kinematic activity profiles of top-class referees can be influenced by the distance covered by the ball; (2) the amount of high-speed running $\left(>5 \mathrm{~m} \cdot \mathrm{s}^{-1}\right.$ ) best describes the physical performance of referees; (3) heart rate recording can be a useful tool to determine the most intense periods of a match and (4) the new fitness tests adopted by FIFA were poor predictors of match activities.
\end{abstract}

Keywords: 2D biomechanical analysis, heart rate, high-intensity activities, physical performance

\section{Introduction}

Abundant data have been reported during the last ten years on kinematics of match activities (Castagna \& Abt, 2003; Castagna, Abt, \& D'Ottavio, 2004; Krustrup \& Bangsbo, 2001; Mallo, Navarro, GarcíaAranda, Gilis, \& Helsen, 2007), physiological responses during match play (D'Ottavio \& Castagna, 2001; Helsen \& Bultynck, 2004) and physical capacity (Castagna, Abt, \& D'Ottavio, 2002a, 2002b, 2005; Castagna \& D'Ottavio, 2001) of association football referees. Nevertheless, it is essential to examine the factors that might influence the physical performance of referees during competition. In a recent study, Weston, Bird, Helsen, Nevill, and Castagna (2006) suggested that match intensity, calculated from heart rate recordings and ratings of perceived exertion, was higher in the Premier League than in other English Football League matches. However, in this study, no kinematic variables were examined during match play. It has also been observed that the performance of intense exercise by players is related to the standard of competition (Bangsbo, Norregaard, \& Thorso, 1991; Ekblom, 1986; Mohr, Krustrup, \& Bangsbo, 2003), so the extent to which the participation of players of different standard affects the kinematics of referees is uncertain.

Accompanying the match standard, movements of officials are partly related to the number of high-intensity runs performed by players (Weston, Castagna, Impellizzeri, Rampinini, \& Abt, 2007), However, it is also unclear if movements of the ball could be a better predictor of referees' activity than players' movements. To apply the laws of the game, referees must be close to the area of the field where 
the ball is played so it could be anticipated that, the further the ball travels during matches, the greater is the physical demand on referees to enable them to keep up with play. To our knowledge, this study is the first that has attempted to relate the distance travelled both by the ball and the referee throughout a match.

Heart rate recordings have been used extensively to provide an indicator of the intensity of exercise during refereeing (D'Ottavio \& Castagna, 2001; Helsen \& Bultynck, 2004; Krustrup \& Bangsbo, 2001). However, Weston and Castagna (2005) have recently questioned the use of match heart rates alone as valid measures of exercise intensity, as they did not identify a correlation between heart rate and distance travelled or the number of high-intensity runs performed by referees during matches. As the relationships in Weston and Castagna's (2005) study were explored for the entire 90-min of play, it appears important to examine the relationships during shorter (5-min) periods throughout the matches.

The relationship between performance tests and key indices of match performance has been reported (Castagna \& D'Ottavio, 2001; Krustrup \& Bangsbo, 2001; Krustrup, Mohr, \& Bangsbo, 2002). Recent studies (Castagna et al., 2002a; Mallo et al., 2007) have shown low correlations between the results of match officials on traditional fitness tests used by FIFA (a $2 \times 50 \mathrm{~m}$ and a $2 \times 200 \mathrm{~m}$ sprint test and a 12 -min running test) and match activities. The refereeing department of FIFA is concerned how to improve the performance of referees, and therefore in the FIFA Confederations Cup 2005 new fitness tests were introduced to assess the physical capacity of officials in a way that is much more in line with the match performances. For this reason, the new tests are based on intermittent exercise in an attempt to replicate with improved sensitivity referees' activity patterns during competition and evaluate both the ability to perform repeated sprints and the capacity to perform repeated intense-interval runs. As highintensity running has been shown to reflect more accurately the physical demands of soccer refereeing, the question arises to what extent are these new tests useful to examine the fitness of referees and predict the amount of their high-intensity running during competition?

Therefore, the aims of this study were to:

1. Determine the effect of match standard and movements of the ball on the kinematic performance of top-class referees;

2. Relate kinematic and heart rate responses in 5min periods during the matches; and

3. Examine the relationship between the new field tests adopted by FIFA to individual physical match performances.

\section{Methods}

\section{Anthropometry}

Eleven top-class referees (mean age 39.32, $s=3.43$ years; stature 1.83, $s=0.04 \mathrm{~cm}$ and body mass $78.82, s=4.49 \mathrm{~kg}$ ) participated. All referees had held FIFA licenses for $8.05, s=3.39$ years at international standard. Written consent from the refereeing department and from all the referees was obtained before the beginning of the tournament, following an explanation of the nature of the research.

\section{Experimental design}

All measurements were carried out in a two-week period during the FIFA Confederations Cup, held in Germany in June 2005. This was a high-standard competition that involved the six national teams that had won previous continental tournaments (Greece, Japan, Tunisia, Mexico, Argentina and Australia), the 2002 World Cup champions (Brazil) and the 2006 World Cup host nation (Germany).

From the total number of 16 games during the tournament, match analyses and heart rate recordings were obtained in 9 and 12 matches, respectively. In 7 of these matches, kinematic and cardiovascular responses were simultaneously recorded in 7 referees. All referees who took part in the championship completed the fitness tests before the start of the event. Figure 1 represents an overview of the experimental design.

Kinematic data obtained during the actual research were compared with those presented in a previous study (Mallo et al., 2007) carried out during the under-17 World Championship Finland 2003 that used the same technique for match analysis.

\section{Match analysis}

The kinematic activity profile of the referees was recorded by means of a two-dimensional photogrammetric system that allowed us to determine the positions on the field of play based on video footage (Mallo \& Navarro, 2004; Mallo et al., 2007). Briefly, all matches were filmed using three digital videocameras strategically positioned at the main stand of

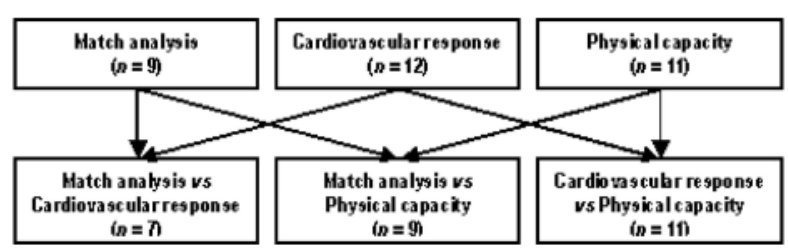

Figure 1. Overview of the experimental design. $(n)=$ number of subjects. 
the stadia and, after the end of the match, the video recordings were played-back, synchronised and stored on the hard-disk of a computer. The vertical projection of the referees' centre of mass was indicated with the mouse on the computer screen at a frame rate of $1 \mathrm{~Hz}$. The position of the ball was also indicated in all the frames where it was on the ground. In those frames in which the ball was played in the air, the digitisation of the ball was discarded. In these cases, the starting and finishing position of the ball was indicated in the screen, to calculate the horizontal distance between both positions. All the incidents (foul play, hand balls, direct free kicks, indirect free kicks, etc.) that occurred during the match and that were indicated by the referee were captured and digitised at a frame rate of $25 \mathrm{~Hz}$. Both the position of the referee and the location where an infringement occurred were digitised. The incidents were classified according to time and zone in the field (Krustrup \& Bangsbo, 2001; Mallo et al., 2007). The calibration system was also digitised and 2D-DLT based algorithms (after Abdel-Aziz \& Karara, 1971) were used to transform screen-displayed coordinates to real coordinates. These coordinates were smoothed using quintic-spline functions with the "Cross Generalised Validation" procedure to evaluate the adjustment factor (Woltring, 1985).

Movement distances and speeds were calculated from the spline polynomial functions. The movements of the referee were classified into the following categories (based on Mallo et al., 2007): (a) standing still $\left(<1 \mathrm{~m} \cdot \mathrm{s}^{-1} ;<3.6 \mathrm{~km} \cdot \mathrm{h}^{-1}\right)$; (b) walking (1.01-2 $\left.\mathrm{m} \cdot \mathrm{s}^{-1} ; 3.61-7.20 \mathrm{~km} \cdot \mathrm{h}^{-1}\right)$; (c) jogging $\left(2.01-3.60 \mathrm{~m} \cdot \mathrm{s}^{-1} ; 7.21-13 \mathrm{~km} \cdot \mathrm{h}^{-1}\right)$; (d) cruising $\left(3.60-5 \mathrm{~m} \cdot \mathrm{s}^{-1} ; 13.01-18 \mathrm{~km} \cdot \mathrm{h}^{-1}\right)$ and (e) high-speed running $\left(>5 \mathrm{~m} \cdot \mathrm{s}^{-1}\right.$; $>18 \mathrm{~km} \cdot \mathrm{h}^{-1}$ ). The high-intensity activities represented the movements performed at speeds greater than $3.60 \mathrm{~m} \cdot \mathrm{s}^{-1}\left(13 \mathrm{~km} \cdot \mathrm{h}^{-1}\right)$. Performance throughout the matches was expressed in 5-, 15and 45-min intervals.

The validity and reliability of this method for match-analysis has been reported in a previous study (Mallo et al., 2007). To assess the validity, a referee covered different circuits in a football field at paced speeds that simulated typical movements during a match. Distances measured on the field of play were compared with those obtained by the photogrammetric system and agreement was within $1.5 \%$ for all the categories studied $(P>0.05)$. The root mean square error (Allard, Blanchi, \& Aïssaqui, 1995) for reconstructed distances between two points was $1.98 \%$. Intra- and inter-rater reliability assessments carried out by trained observers did not reveal any differences $(P>0.05)$ between measurements, with total differences in the kinematic data always being less than $1 \%$.

\section{Heart rate}

Heart rate was recorded by means of short-range radio telemetry (Polar Team System, Kempele, Finland). This system is specially designed for team sports and consists of a chest monitor that records and stores the heart rate signal at 5-s intervals. In contrast to the traditional systems, wearers do not require a receiver on their wrist. The chest monitor was placed on the referees' body in their dressing room before starting the warm-up for the match. Once the game was over, the data were downloaded to a computer using the Polar Precision 3.0 software (Polar, Kempele, Finland). Although all the referees were encouraged to use the heart rate monitor during the matches, 12 observations were obtained from the total of 16 matches of the championship.

Data were processed and expressed in relation to the individual maximal heart rate $\left(\mathrm{HR}_{\max }\right)$ of the participants. As referees used heart rate monitors during matches, fitness tests and training sessions, peak values reached in any of the 5-s intervals in these conditions were determined as individual $\mathrm{HR}_{\text {max }}$. In line with Helsen and Bultynck (2004), five activity categories were used to classify the efforts according to the percentage of $\mathrm{HR}_{\max }$ : (i) passive recovery $\left(<65 \% \mathrm{HR}_{\max }\right)$; (ii) active recovery (66$75 \% \mathrm{HR}_{\max }$ ); (iii) low-intensity $\left(76-85 \% \mathrm{HR}_{\max }\right)$; (iv) high-intensity $\left(86-95 \% \mathrm{HR}_{\max }\right)$; and maximal effort $\left(>95 \% \mathrm{HR}_{\max }\right)$.

\section{Fitness tests}

As from 2005 on, FIFA introduced new fitness tests before the start of any major tournament to evaluate the fitness of international-standard referees and assistant referees. Three days before the tournament, all the officials performed two fitness tests on an athletic track during a 90-min session. To assess the mean running speed during repeated sprints over a specific match distance, referees first completed a $6 \times 40 \mathrm{~m}$ sprint test, with $1 \mathrm{~min} 30 \mathrm{~s}$ recovery between each and every trial. The referees' starting position was $1.5 \mathrm{~m}$ behind the first set of photoelectric beams. All the sprints had to be completed in a maximum time of $6.4 \mathrm{~s}$ (reference time in 2005; $6.2 \mathrm{~s}$ from $2006 \mathrm{on}$ ). The sprints were performed on a regular athletic track and the use of spikes was not allowed. If a referee failed one of the sprints, he was allowed an extra sprint after the regular course of six sprints. However, if the referee did not succeed twice to run below the reference time, they failed the test. After a recovery period of 6-8 $\mathrm{min}$, in the second test - the interval test - the ability to perform intense runs was evaluated. Specifically, referees alternated between running $150 \mathrm{~m}$ in $30 \mathrm{~s}$ and walking $50 \mathrm{~m}$ in $40 \mathrm{~s}$, round the $400-\mathrm{m}$ athletic track (Figure 2). 


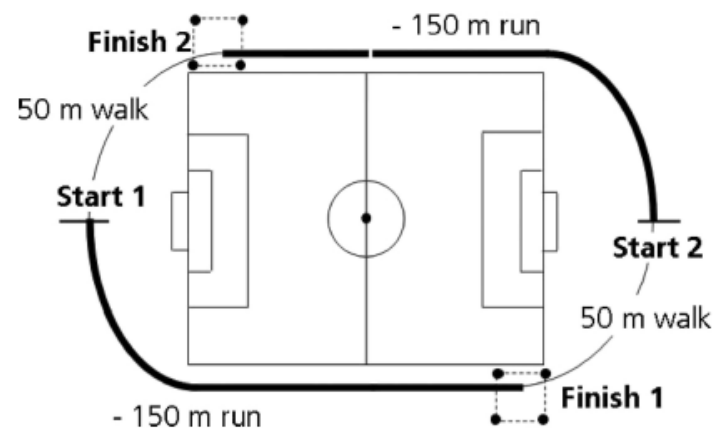

Figure 2. The layout of the "interval test".

Two runs were alternated with two recovery periods. The recovery time was $40 \mathrm{~s}$ in 2005 ( $35 \mathrm{~s}$ from 2006 on). The running speed was $5 \mathrm{~m} \cdot \mathrm{s}^{-1}$ $\left(18 \mathrm{~km} \cdot \mathrm{h}^{-1}\right)$. Time to reach the walking area was indicated by an audio signal. Each referee was instructed to arrive before the whistle in the "walking area" that was marked by four cones $(3 \mathrm{~m}$ in front and $3 \mathrm{~m}$ ahead of the $150 \mathrm{~m}$ mark). Referees could not leave the $50-\mathrm{m}$ "walking area" before the next whistle. Therefore, assistant test leaders were positioned at the start lines with a flag in their hands. Until the next whistle, they blocked the lane on the track by keeping the flag horizontal. On the whistle, they quickly lowered the flag so that the referees could start running. The flag only went down on the whistle. Referees were required to complete a minimum of 10 laps to pass the test, which represents 20 consecutive runs $(4000 \mathrm{~m}$ in total of which $3000 \mathrm{~m}$ consisted of running). The maximum number of laps was 12 that was equivalent to 24 runs. If a referee failed to put their whole body into the walking area before the whistle, they received a verbal caution. If a referee failed to enter the "walking area" twice, they failed the test and were removed immediately. All officials wore heart rate monitors for the duration of the fitness test. Heart rate was recorded at 5-s intervals. Polar Precision software was used for data processing.

\section{Data analysis}

Data are presented as means and standard deviation of the mean $(s)$. Comparisons between two sets of data were carried out using paired $t$-tests. For the analysis of physical and cardiovascular demands during match play, a two-way analysis of variance (ANOVA) compared the distance covered, highintensity activities, distance from infringements and heart rate using a 3 (intervals: $0-15,16-30,31-$ 45) $\times 2$ (period: first, second half) design with repeated measures on both factors. To examine further activity profiles between both halves, a twoway ANOVA was performed using a 5 (activity category: standing still, walking, jogging, cruising and high-speed running) $\times 2$ (period: first, second half) for the kinematic data and a 5 (activity category: passive recovery, active recovery, lowintensity, high-intensity, maximal effort) $\times 2$ (period: first, second half) design for heart rate, with repeated measures on both factors. To compare effects of match-standard on referees' activity profiles we carried out a two-way ANOVA using a 2 (championship: U-17 World Championship 2003, Confederations Cup 2005) $\times 5$ (activity category: standing still, walking, jogging, cruising and highspeed running) design with repeated measures on the last factor. In addition to the sprint times and running distance on the interval test, we also recorded the mean heart rate (absolute and percentage of individual $\mathrm{HR}_{\max }$ ) and recovery heart rate (heart rate at the end of the test - heart rate $1 \mathrm{~min}$ later) for further analysis of the fitness test results. All the repeated measures ANOVAs were carried out after ensuring the sphericity assumption was not violated. Geisser/Greenhouse correction was used to adjust the degrees of freedom when epsilon was less than 0.75 (Thomas \& Nelson, 2001). Correlation coefficients $(r)$ were determined and tested for significance using Pearson's regression test. Statistical significance was set at $P \leq 0.05$ for all the statistical tests. This value was adjusted by the Bonferroni correction when carrying out multiple relationships. Post hoc analyses were performed using Scheffé tests. The meaningfulness of the difference between two means was determined by the effect (size (mean 1-mean 2) $\cdot s^{-1}$ ) (Cohen, 1969, in Thomas \& Nelson, 2001).

\section{Results}

\section{Kinematic activity}

Match activities. Total distance covered during matches was $10,218, s=643 \mathrm{~m}$, with no difference between both halves (5178, $s=363$ vs. 5040, $s=398 \mathrm{~m} ; P=0.34$ ).

Table I shows the distance covered by different movement categories in both match periods, with no interaction detected between the activities performed in the two halves $\left(F_{4,32}=2.15 ; P=0.10\right)$. Referees stood or walked for $37.1, s=3.5$ and $26.0, s=1.8 \%$, respectively, of matches. Medium-intensity activity (jogging) represented 20.2, $s=2.1 \%$, whereas the remaining time was spent cruising $(8.9, s=1.2 \%)$ and high-speed running $(7.7, s=1.5 \%)$. The repeated measures ANOVA did not reveal any category interaction between both 45 -min periods $\left(F_{4,32}=1.22 ; P=0.32\right)$.

After the 5-min interval of each half during which the referees performed the most high-speed running 
Table I. Distance covered (m) at different speeds during both halves of a match (mean and standard deviation).

\begin{tabular}{lccr}
\hline & First half & Second half & Overall \\
\hline Standing still & $1,004 \pm 16$ & $973 \pm 113$ & $1,977 \pm 187$ \\
Walking & $1,120 \pm 114$ & $1,064 \pm 85$ & $2,184 \pm 162$ \\
Jogging & $1,310 \pm 153$ & $1,216 \pm 135$ & $2,526 \pm 230$ \\
Cruising & $812 \pm 97$ & $798 \pm 129$ & $1,611 \pm 204$ \\
High-speed running & $932 \pm 174$ & $989 \pm 238$ & $1,920 \pm 399$ \\
Total & $5,178 \pm 363$ & $5,040 \pm 398$ & $10,218 \pm 643$
\end{tabular}

(37, $s=7 \mathrm{~s})$, during the following $5 \mathrm{~min}$, time spent performing exercise in this locomotive category was reduced $50 \%(18, s=8 \mathrm{~s} ; P<0.001)$. This value was $19 \%$ lower $(P=0.01)$ than the 5 -min mean of the game $(23, s=6 s$ ) (Figure 3 ).

Match standard. The results of the two-way ANOVA showed an effect for match standard $\left(F_{1,19}=5.25\right.$; $P=0.03)$ and a match-standard $x$ activity-category interaction $\left(F_{4,76}=42.65 ; P<0.001\right)$. Figure 4 shows that during the senior high-standard games, referees increased the volume of activities carried out at minimal (standing still; $P<0.001$ ) and maximal (high-speed running; $P=0.02$ ) intensities. Specifically, referees increased $37 \%$ of the distance covered by high-speed running from $1405, s=453 \mathrm{~m}$ to 1920, $s=399 \mathrm{~m}$ (effect size: 1.19). Conversely, distances travelled walking $(P=0.01)$ and jogging and cruising $(P<0.001)$ were higher during youth refereeing.

Distance covered by the ball. Distance covered by the ball during the first and second half of the match was $11,009, s=1735 \mathrm{~m}$ and $10,706, s=1096 \mathrm{~m}$ respectively, with no differences between both 45 -min periods $(P=0.46)$. The greatest distance travelled by the ball was in the initial $15 \mathrm{~min}$ of the game (3714, $s=631 \mathrm{~m}$ ), although there were no differences with the remaining 15 -min periods ( $P$ at best 0.16 ).

Both total distance covered by referees $(r=0.77$; $P=0.02$ ) and time spent performing high-intensity activities $(r=0.67 ; P=0.05)$ were correlated to the distance travelled by the ball during the matches. Time spent by the referees performing high-intensity activities $(r=0.55 ; P<0.001$; Figure 5$)$ and highspeed running $(r=0.29 ; P=0.03)$ were moderately correlated to the distance travelled by the ball in the same 15-min match period.

Distance from infringements. A total of 304 incidents were analysed, with no differences according to the period in which they were indicated (155 vs. 149 incidents per period; $P=0.54$ ). Mean distance from infringements was $16.3, s=7.4 \mathrm{~m}$. A two-way ANOVA yielded an effect $(P<0.001)$ for the zone

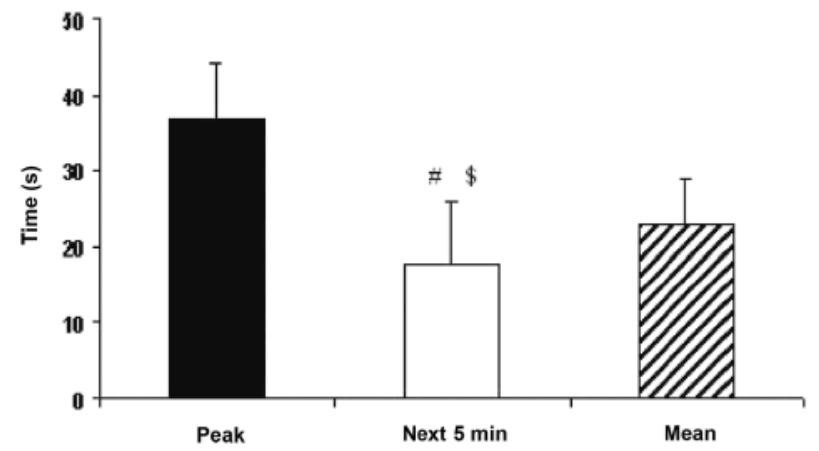

Figure 3. Peak 5-min interval of high-speed running versus the following 5 -min period and the mean 5 -min value for the match (mean and standard deviation). "Different $(P=0.01)$ from mean 5 -min value. ${ }^{8}$ Different $(P<0.001)$ from peak 5 -min value.

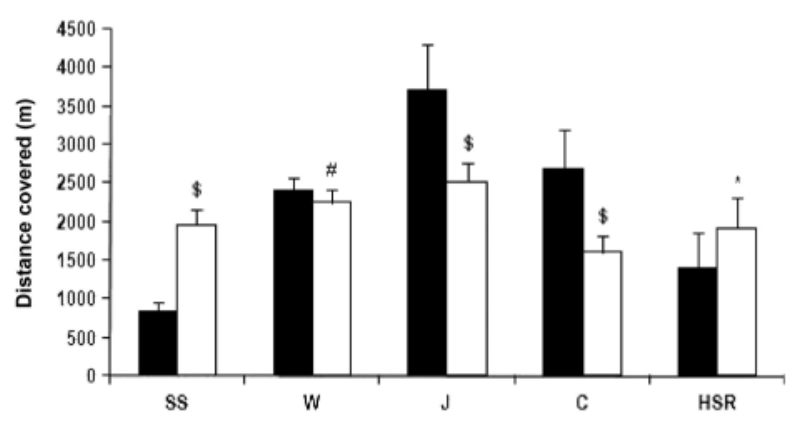

Figure 4. Distance covered at different speeds (mean and standard deviation) during the FIFA U-17 World Championship 2003 (dark bars) and the FIFA Confederations Cup 2005 (light bars). SS, standing still; W, walking; J, Jogging; C, cruising; HSR, highspeed running. ${ }^{\star}$ Different $(P=0.02)$ from U-17 WC. " Different $(P=0.01)$ from U-17 WC. ${ }^{\$}$ Different $(P<0.001)$ from U-17 WC.

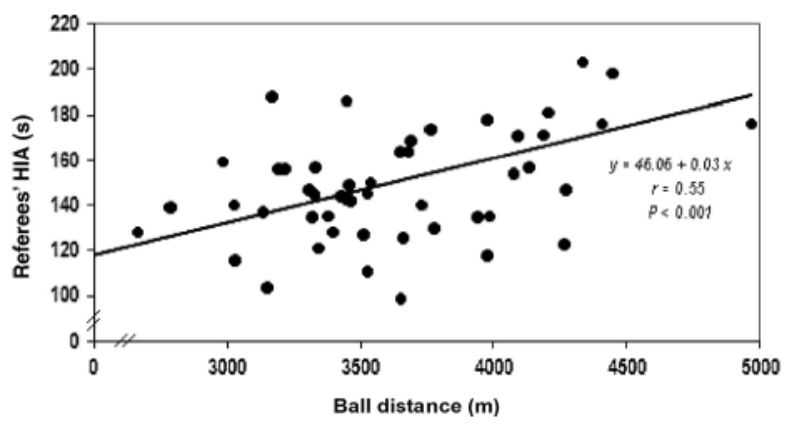

Figure 5. Individual relationship between high-intensities activities performed by the referee and distance covered by the ball in the same 15-min period.

in which the incidents were indicated as mean distance to the infringement was higher in the right attacking zone than in other three zones of the field (right middle, left attacking and left middle zones).

\section{Cardiovascular response}

Heart rate. Mean heart rate $(n=12)$ during the match was $161, s=8 \mathrm{~b} \cdot \mathrm{min}^{-1}$ which corresponds to 86 , 
$s=3 \%$ of the individual $\mathrm{HR}_{\max }$; no difference was detected between halves $(162, s=8$ vs. $160, s=9$ $\left.\mathrm{b} \cdot \mathrm{min}^{-1} ; P=0.25\right)$. Mean time spent by referees exercising in the passive recovery, active recovery, low-intensity, high-intensity and maximal effort categories was $1, s=1 \%, 7, s=7 \%, 35, s=17 \%$, $52, s=20 \%$ and $5, s=6 \%$, respectively. When only the seven matches in which both the kinematic activity and the cardiovascular response were recorded simultaneously were taken into consideration, the two-way ANOVA did not reveal any interaction between the activity categories in both halves of the game $\left(F_{4,24}=1.83 ; P=0.16\right)$.

Relationship between heart rate and kinematic activity profile. There was a relationship $(r=0.60 ; P<0.01$; Figure 6) between mean heart rate (expressed as $\left.\% \mathrm{HR}_{\max }\right)$ and the number of high-intensity activities performed in the same 5-min interval. Mean heart rate was also related to time spent by high-speed running in the same $5-\mathrm{min}$ period $(r=0.50$; $P<0.01)$.

\section{Physical capacity}

Fitness tests. All the referees passed the $6 \times 40 \mathrm{~m}$ sprint test. Mean time for the $40-\mathrm{m}$ sprints was 5.77 , $s=0.17 \mathrm{~s}$, whereas the mean shortest time to complete the distance was $5.70, s=0.17 \mathrm{~s}$.

In addition, all officials reached the minimum mark in the interval test and completed a mean of 23 , $s=1$ runs, with a mean test duration of $26 \min 50 \mathrm{~s}$. Mean heart rate during the test was $171, s=10$ $\mathrm{b} \cdot \min ^{-1}\left(93, s=3 \% \mathrm{HR}_{\max }\right)$. Recovery heart rate had a mean value of $27, s=12 \mathrm{~b}$. Referees exercised at intensities exceeding $85 \% \mathrm{HR}_{\max }$ for $90, s=14 \%$ of the total test time.

Relationship between fitness tests and match activities. Mean $(r=-0.02 ; P=0.96)$ and best $(r=-0.13$; $P=0.74)$ time in the sprint test were poorly related to the distance covered by high-speed running during the matches.

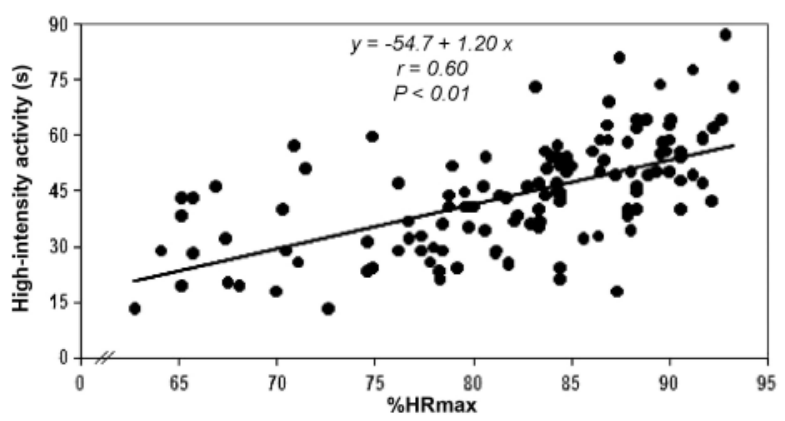

Figure 6. Individual relationship between mean heart rate (expressed as $\% \mathrm{HR}_{\operatorname{maxx}}$ ) and the number of high-intensity activities performed in the same 5-min interval.
Mean heart rate during the interval test was not correlated to total distance covered $(r=-0.07$; $P=0.85)$ and to time spent running at high speed $(r=-0.49 ; P=0.18)$ during the matches. Time spent during this test exercising at any heart rate zone was also not correlated ( $P$ at best 0.12 ) with any kinematic variable measured during match play. Only the recovery heart rate after the interval test showed a moderate correlation with the time spent moving at high-intensities during the games $(r=0.70 ; P=0.04)$.

Relationship between fitness tests and match heart rate recordings. Mean heart rate during the interval test was correlated to mean heart rate $(r=0.42 ; P=0.18)$ and the time spent exercising at intensities exceeding $85 \% \mathrm{HR}_{\max }(r=0.38 ; P=0.22)$ during the matches. Additionally, time spent in this heart-rate zone in the test and in matches was not correlated $(r=0.25$; $P=0.44)$. Recovery heart rate after the interval test was correlated with the time spent by referees during the matches in the high-intensity category, that is between 86 and $95 \%$ of individual $\mathrm{HR}_{\max }$ $(r=-0.53 ; P=0.08)$.

\section{Discussion}

In this study, we have described the physical demands experienced by top-class association football referees during an international high-standard FIFA tournament. Referees covered $\sim 10.2 \mathrm{~km}$ during matches with almost $19 \%$ of this by highspeed running $\left(>5 \mathrm{~m} \cdot \mathrm{s}^{-1}\right)$. Both total distance and high-intensity activities were related to the distance travelled by the ball during the match. Distance covered by high-speed running seems to be the best kinematic performance discriminator for refereeing, as the referees examined during the present study ran at high-speed $37 \%$ further than those examined during the U-17 2003 World Championship. After the 5-min match interval where referees performed the most intense exercise, physical performance was reduced in the next $5 \mathrm{~min}$. This indicates that the referees experience temporary fatigue in the course of the game. Mean heart rate during a match was 161 $\mathrm{b} \cdot \min ^{-1}\left(86 \%\right.$ of the individual $\left.\mathrm{HR}_{\max }\right)$. Mean heart rate during a 5-min period was related to the high-intensity activities performed in the same interval, suggesting that heart-rate recordings could be used as a complementary indicator of the intense exercise episodes of the match. In addition, the new fitness tests adopted by FIFA were poor predictors of match activities.

In 2003, we started a research project with the FIFA refereeing department to provide scientific support to referees (Mallo et al., 2007) and assistant referees (Mallo, Navarro, García-Aranda, Gilis, \& Helsen, 2008) to prepare them for international tournaments. 
Even though only few top-class officials take part in these tournaments, their evaluation can be valuable as it is likely that even minimum demand placed on referees are severe (Bangsbo, 1994). Distance travelled $(10.2 \mathrm{~km})$ and the mean heart rate $(86 \%$ $\mathrm{HR}_{\text {max }}$ ) of referees during the matches from the FIFA Confederations Cup 2005 are in the range of what has been recently reported in the literature: $10-12 \mathrm{~km}$ (Castagna et al., 2004; Krustrup \& Bangsbo, 2001; Mallo et al., 2007) and $85-90 \% \mathrm{HR}_{\max }$ (D'Ottavio \& Castagna, 2001; Helsen \& Bultynck, 2004; Krustrup \& Bangsbo, 2001), indicating that the demands experienced when refereeing matches that involve elite national teams are much like the physical requirements of top-standard clubs refereeing.

Nevertheless, these parameters can serve only as general estimators of the exercise intensity as it has been suggested that the production of intense exercise is a more valid measurement of physical performance when officiating (Castagna \& Abt, 2003; Krustrup \& Bangsbo, 2001). The distances covered at different speeds in the present championship were compared with those presented in a previous paper (Mallo et al., 2007) using the same technique for match analysis and revealed that referees covered a higher meaningful distance (effect size: 1.19; Figure 4) by high-speed running at senior high-standard matches than in youth games. This inter-tournament comparison supports previous research carried out with elite Italian players (Mohr et al., 2003) and Italian (Castagna et al., 2004) and English referees (Weston et al., 2006) and suggests that the physical demands are age-dependent. Distance covered at speeds exceeding $5 \mathrm{~m} \cdot \mathrm{s}^{-1}$ during the Confederations Cup was practically identical to that reported for Italian referees (Castagna \& D'Ottavio, 2001; Castagna et al., 2002a,b): 1920 vs. $1913-1978 \mathrm{~m}$, respectively. Top-class referees observed in the present study seemed to develop a peculiar effort profile, with a more economical usage of their energy, because as they increased the amount of maximal activities carried out, they spent more time standing still. Thus, it is likely that an overall higher tempo of matches requires referees to possess higher fitness to enable them to keep pace. However, reductions in movement after intense 5-min periods during matches occurred even though no differences were detected in distances covered by the ball during these periods of relative rest. Notably, and in contrast to previous studies (Mallo et al., 2007; Mohr et al., 2003), this phenomenon occurred after the most intense periods in both halves, suggesting that referees can be exposed to this kind of temporary fatigue at different stages of the match.

In this study, we have found an important relationship between the distance covered by the ball and the kinematic performance of the referee (distance covered and high-intensity activities). To our knowledge, this is the first time that movements of the ball have been taken into consideration and related to referees' movements. Reilly (1997) suggested that the "direct method" of play could increase physiological demands on players. During the present tournament, the ball travelled $21 \%$ further during matches that involved the national teams of Greece and Japan ("direct method" of play) than in those that involved Argentina and Brazil ("passing game"), indicating that tactics used by the teams influences activity profiles of referees. A recent study (Weston et al., 2007) has also shown how players' intensities of exercise affect referees' activity. Probably, the combination both of distance covered by the ball and number of high-intensity activities performed by players, is key to determining overall physical match intensity experienced by referees. For that reason, it seems a major challenge for future studies to integrate these variables as they can serve as a performance indicator and aid comparisons between studies. It appears also essential to examine the speed at which the ball is played, because it is likely that the top-class teams play the ball faster and so increase demands placed both on officials and players to keep up with the tempo of the game.

In addition to simultaneous comparison of kinematics between tournaments and registration of movements of the ball, another advantage of the technique used in the present study was that it allowed the introduction of other external variables such as heart-rate responses. The use of heart rate per se as an indicator of exercise intensity for the referees has been questioned recently by Weston and Castagna (2005). Reinforcing the observations from these authors, in the present study we did not find a meaningful correlation between mean heart rate and total distance covered and high-intensity activities for whole matches. However, when comparisons were made in shorter periods (5-min), a moderate correlation was observed between mean heart rate (expressed as a $\left.\% \mathrm{HR}_{\max }\right)$ and the number of high-intensity activities performed (Figure 6). These findings suggest that the use of the heart rate data can predict match periods where the referees are more active and perform more high-intensity exercise, but mean heart rate cannot be used on its own as a global indicator of competition intensity as it can be affected by other factors (Achten \& Jeukendrup, 2003).

The low correlation determined between the traditional battery of fitness tests used by FIFA $(2 \times 50 \mathrm{~m}$ and $2 \times 200 \mathrm{~m}$ sprint tests and $12-\mathrm{min}$ running test) and match activities (Castagna et al., 2002a; Krustrup \& Bangsbo, 2001; Mallo et al., 2007) led FIFA's Refereeing Department to adopt new field tests to evaluate the fitness of top-class referees. The strength of correlations found in this 
study do not support the construct validity of these new tests. Specifically, the heart-rate data during the interval test were not relevantly correlated to total match distance and to distance covered by highspeed running. Conversely, recovery heart rates after the interval test showed a higher correlation with the number of high-intensity activities performed during the match and to the time spent exercising at intensities between 86 and $-95 \% \mathrm{HR}_{\max }$. This means that referees with better heart rate recovery after the interval test produced more intense exercise during the match without needing to spend so much time between 86 and $95 \% \mathrm{HR}_{\max }$, as they had a better recovery in between high-intensity activities. The mean intensity $\left(93 \% \mathrm{HR}_{\max }\right)$ and the fact that referees exercised for more than $24 \mathrm{~min}$ at intensities exceeding $85 \% \mathrm{HR}_{\max }$ suggests that the test challenged cardiovascular function in officials. Thus, FIFA could use these tests normatively - officials must reach a minimum score - but not as a predictive tool of match demands. Nevertheless, further investigations are required to determine other physiological responses during the test along with its validity and reliability. In this respect, it would be valuable to compare fitness test performances on an athletic track, which appears to be a FIFA requirement, with the results on the Yo-Yo intermittent recovery test. To our knowledge, this is the best field test that has been developed to assess physical capabilities of referees relevant to match demands (Krustrup \& Bangsbo, 2001; Krustrup et al., 2003) and it has also been demonstrated to discriminate between standards of referees (Castagna et al., 2005).

In summary, the present study demonstrated that the kinematic demands of officiating matches that involve elite national teams are much like the kinematic requirements of the top-standard club refereeing and can be affected by the playing style of teams, that is, the way they move the ball in the field. In addition, the standard of competition also influences the physical performance of referees as they have to produce more high-speed running to follow the pace of play. It was also shown that the use of heart rate recordings can help to predict the most intense periods of the match but cannot serve as indicators of the global intensity of the exercise. In addition, we found that the new field tests adopted by FIFA were poorly correlated to match activities.

\section{Acknowledgements}

This study was supported by the Refereeing Department of the Fédération Internationale de Football Association. We would also like to thank FIFA's Medical Assessment and Research Center (F-MARC) for their financial support in this project. The cooperation of the referees was also of invaluable importance.

\section{References}

Abdel-Aziz, Y. I., \& Karara, H. M. (1971). Direct linear transformation from comparator coordinates into space coordinates in close range photogrammetry. In The American Society of Photogrammetry (Eds.), Proceedings of the Symposium on close range photogrammetry (pp. 1-18). Falls Church, VA: ASP.

Achten, J., \& Jeukendrup, A. (2003). Heart rate monitoring: applications and limitations. Sports Medicine, 33, 517-538.

Allard, P., Blanchi, J. P., \& Aissaqui, R. (1995). Bases of threedimensional reconstruction. In P. Allard, I. A. F. Stokes \& J. P. Bianchi (Eds.), Three dimensional analysis of human movement (pp. 19-40). Champaign, IL: Human Kinetics.

Bangsbo, J. (1994). The physiology of soccer - with special reference to intense intermittent exercise. Acta Physiologica Scandinavica, 151 (Suppl. 619), 1-156.

Bangsbo, J., Norregaard, L., \& Thorso, F. (1991). Activity profile of competition soccer. Canadian foumal of Sports Science, 16, 110-116.

Castagna, C., \& Abt, G. (2003). Intermatch variation of match activity in elite Italian soccer referees. Fournal of Strength and Conditioning Research, 17, 388-392.

Castagna, C., \& D'Ottavio, S. (2001). Effect of maximal aerobic power on match performance in elite soccer referees. Fournal of Strength and Conditioning Research, 15, 420-425.

Castagna, C., Abt, G., \& D'Ottavio, S. (2002a). Relation between fitness tests and match performance in elite Italian soccer referees. Fournal of Strength and Conditioning Research, 16, 231-235.

Castagna, C., Abt, G., \& D'Ottavio, S. (2002b). The relationship between blood lactate thresholds and match performance in elite soccer referees. Fournal of Strength and Conditioning Research, 16, 623-627.

Castagna, C., Abt, G., \& D'Ottavio, S. (2004). Activity profile of international-level soccer referees during competitive matches. foumal of Strength and Conditioning Research, 18, 486-490.

Castagna, C., Abt, G., \& D'Ottavio, S. (2005). Competitive-level differences in Yo-yo intermittent recovery and twelve minute run test performance in soccer referees. Fournal of Strength and Conditioning Research, 19, 805-809.

D'Ottavio, S., \& Castagna, C. (2001). Physiological load imposed on elite soccer referees during actual match play. Fournal of Sports Medicine and Physical Fitness, 41, 27-32.

Ekblom, B. (1986). Applied physiology of soccer. Sports Medicine, $3,50-60$.

Helsen, W. F., \& Bultynck, J. B. (2004). Physical and perceptualcognitive demands of top-class refereeing in association football. foumal of Sports Sciences, 22, 179-189.

Krustrup, P., \& Bangsbo, J. (2001). Physiological demands of topclass soccer refereeing in relation to physical capacity: effect of intense intermittent exercise training. fournal of Sports Sciences, 19, 881-891.

Krustrup, P., Mohr, M., \& Bangsbo (2002). Activity profile and physiological demands of top-class soccer assistant refereeing in relation to training status. fournal of Sports Sciences, 20, 861-871.

Krustrup, P., Mohr, M., Amstrup, T., Rysgaard, T., Johansen, J., Steensberg, A., et al. (2003). The Yo-yo intermittent recovery test: physiological response, reliability and validity. Medicine and Science in Sports and Exercise, 35, 697-705.

Mallo, J., \& Navarro, E. (2004). Analysis of the load imposed on under-19 soccer players during some typical football training drills. Fournal of Sports Sciences, 22, 510-511.

Mallo, J., Navarro, E., García-Aranda, J. M., Gilis, B., \& Helsen, W. (2007). Activity profile of top-class soccer referees in relation to performance in selected physical tests. Fournal of Sports Sciences, 25, 805-813.

Mallo, J., Navarro, E., García-Aranda, J. M., Gilis, B., \& Helsen, W. (2008). Analysis of the kinematical demands imposed on top-class assistant referees during competitive soccer matches. foumal of Strength and Conditioning Research, 22, 235-242. 
Mohr, M., Krustrup, P., \& Bangsbo, J. (2003). Match performance of high-standard soccer players with special reference to development of fatigue. Fournal of Sports Sciences, 21, 519-528.

Reilly, T. (1997). Energetics of high-intensity exercise (soccer) with particular reference to fatigue. Fournal of Sports Sciences, 15, 257-263.

Thomas, J. R., \& Nelson, J. K. (2001). Research methods in physical activity. Champaign, IL: Human Kinetics.

Weston, M., Bird, S., Helsen, W., Nevill, A., \& Castagna, C. (2006). The effect of match standard and referee experience on the objective and subjective mach workload of English Premier League referees. Fournal of Science and Medicine in Sport, 9, 256262.
Weston, M., \& Castagna, C. (2005). The relationship between heart rate and intensity of match play in soccer referees. fournal of Sports Sciences, 23, 1302-1303.

Weston, M., Castagna, C., Impellizzeri, F. M., Rampinini, E., \& Abt, G. (2007). Analysis of physical match performance in English Premier League soccer referees with particular reference to first half and player work rates. Foumal of Science and Medicine in Sport, 10, 390-397.

Woltring, H. J. (1985). On optimal smoothing and derivate estimation from noisy displacement data in biomechanics. Human Movement Sciences, 4, 229-245. 